\title{
Numerical modeling of two-dimensional simulation of groundwater protection from lead using different sorbents in permeable barriers
}

\author{
Zehraa B. Masood, Ziad Tark Abd $\mathrm{Ali}^{\dagger}$ \\ Environmental Engineering Department, College of Engineering, University of Baghdad, Baghdad, Iraq
}

\begin{abstract}
This study is to investigate the possibility of using activated carbon prepared from Iraqi date-pits (ADP) which are produced from palm trees (Phoenix dactylifera L.) as low-cost reactive material in the permeable reactive barrier ( $\mathrm{PRB})$ for treating lead $\left(\mathrm{Pb}^{+2}\right)$ from the contaminated groundwater, and then compare the results experimentally with other common reactive materials such as commercial activated carbon (CAC), zeolite pellets (ZP). Factors influencing sorption such as contact time, initial $\mathrm{pH}$ of the solution, sorbent dosage, agitation speed, and initial lead concentration has been studied. Two isotherm models were used for the description of sorption data (Langmuir and Freundlich). The maximum lead sorption capacities were measured for ADP, CAC, and ZP and were found to be $24.5,12.125$, and $4.45 \mathrm{mg} / \mathrm{g}$, respectively. The kinetic data were analyzed using various kinetic models particularly pseudo-first-order, pseudo-second-order, and intraparticle diffusion. COMSOL Multiphysics 3.5a depend on finite element procedure was applied to formulate transmit of lead $\left(\mathrm{Pb}^{+2}\right)$ in the two-dimensional numerical (2D) model under an equilibrium condition. The numerical solution shows that the contaminant plume is hindered by PRB.
\end{abstract}

Keywords: Iraqi date-pits, Isotherm, Lead, Permeable barriers, Sorption, Transport

\section{Introduction}

Toxic heavy metals that existence in groundwater caused harmed water sources and should be averted to keep the environmental feature. Heavy metals, for example, chromium, lead, and mercury which are associated with the human resources and their compounds are very toxic [1]. Lead is among the most toxic metals, ranks second in the list of prioritized hazardous substances issued by the US Agency for Toxic Substances and Disease Registry [2]. Lead is considered a useful component that inters in many industries such as lamination, dyes, lead-acid storage batteries, ceramic industries, chemicals products, printing, lead smelting, industry of automobile, and chemical materials spills [3]. Because lead is one of the important pollutants produced by the battery factories, and one of these factories is located near the area of interest, so the lead was chosen as a target for this research. Groundwater may be contaminated with contaminants that come from discarding sites, municipal landfills, filling station, airport, and farming, this pollutant be able to migrate either downward direction in the zone of unsaturated, and arrive at the groundwater or migrate horizontally as a dilute solution, also cause a pollution of surface water [4]. The conventional techniques used to treat contaminated groundwater were the pump and treat (P\&T) technology [5]. This system is complex, highly expensive, and ineffectual in many times in treating adequate contaminant to bring the groundwater to drinking water limits in suitable time limits. The first causes for the breakdown of P\&T technology are the disability to remove all the pollutant from the groundwater is because of hydrogeologic parameters and the residue contaminant mass remains trapped. Therefore, the PRB technique can be considered as an alternate process used to treat groundwater from many kinds of contaminants. It has been treated the contaminant in the groundwater, low energy required, lower operation and servicing costs and little oversight costs [6]. Different types of reactive materials such as activated carbon, zeolite, zero-valent iron (ZVI), and sludge, had been used in many research as reactive materials in PRB such as [7-10]. Commercial activated
This is an Open Access article distributed under the terms of the Creative Commons Attribution Non-Commercial License (http://creativecommons.org/licenses/by-nc/3.0/) which permits unrestricted non-commercial use, distribution, and reproduction in any medium, provided the original work is properly cited.

Copyright (C) 2020 Korean Society of Environmental Engineers
Received June 7, 2019 Accepted August 27, 2019

${ }^{\dagger}$ Corresponding author

Email: z.teach2000@yahoo.com

Tel: +96-479-0343-3954

ORCID: 0000-0001-9834-7122 
carbons (CAC) are known as very effective adsorbent due to their highly developed porosity, large surface area, variable characteristics of surface chemistry, and a high degree of surface reactivity [11]. Because of its high cost compared to other sorbents, many studies have developed a very low-cost sorbent, especially by utilizing waste materials, such as date pits, fruit stones, olive stones and walnut shells which are considered low-cost adsorbents and easily available [12]. The date pits are agricultural wastes formed in a large amount in several regions of Iraq. The Ministry of Planning /Iraq registered that the yearly production of date pits equal to 645,000 tons in the summer of 2009. So, reusing of this agricultural waste as a reactive material is attractive in terms of sustainable development, and also reduced disposal costs. There are much research that dealt with the PRBs [13-16], but the main feature of this study is the use of more than one reactive material and trying to compare theoretically the performance of each one of them in a permeable barrier for remediation of contaminated groundwater using COMSOL Multiphysics 3.5a (2008) software as a tool to solve numerically the advection-dispersion equation that describe the transport of contaminants in porous media. This program is a powerful interactive environment for modeling and solving all kinds of scientific and engineering problems based on partial differential equations (PDE). It runs the finite element analysis together with adaptive meshing and error control using a variety of numerical solvers. Solver and simulation software were used for solving various systems of time-dependent or stationary second order in space PDE. Supported mesh types include 2D (triangular/quadrilateral) and 3D (tetrahedral/hexahedral/ and prism) meshes [17]. Accordingly, the aim of the present work is to: (1) investigate the potential application of activated carbon prepared from Iraqi date pits ( $\mathrm{ADP}$ ) as local and low-cost reactive material for the removal of lead $\left(\mathrm{Pb}^{+2}\right)$ from aqueous solution using PRB, and comparing its potential through batch experiments with other common reactive materials such as $\mathrm{CAC}$ and $\mathrm{ZP}$, and (2) Characterizing the equilibrium transports of $\mathrm{Pb}^{+2}$ theoretically by using COMSOL Multiphysics 3.5a (2008) software based on finite element.

\section{Experimental Work}

\subsection{Materials}

Three materials were chosen as reactive materials for PRB:

- Activated date pits: Iraqi date pits were collected from the date's juice factory and washed manually by using hot distills water in order to take out any unfavorable matter. Date pits have been dehydrated in oven about $24 \mathrm{~h}$ at $105^{\circ} \mathrm{C}$. The dried pits impregnated by using phosphoric acid ( $85 \%$ by weight) with the same ratio of 1:1 (pits:acid), after that $250 \mathrm{~g}$ of pits were placed in a furnace at $500^{\circ} \mathrm{C}$ for $60 \mathrm{~min}$ [18]. After that, the system was cooled down to room temperature, and then washed continuously using warm distilled water until $\mathrm{pH}$ amounted to 6. Finally, the ADP were ground and sieved in the range 1-0.6 $\mathrm{mm}$. The geometric mean diameter was given as $d_{g m}=\left(d_{1} d_{2}\right)^{1 / 2}$ which $\mathrm{d}_{1}$ and $\mathrm{d}_{2}$ are the diameters of the lower and upper sieve, respectively [19].

- CAC: Supplied by "BDH, ANALAR, England", crushed, sieved into 1-0.6 mm, and after that, it should be washed by distilled water before being used to remove fine powder and then dried in the oven about $3 \mathrm{~h}$ at $100^{\circ} \mathrm{C}$.

-ZP: were manufactured by "Dwax Company for Synthetic Zeolite", sieved into 1-0.6 mm, and washed with $1 \mathrm{M}$ of $\mathrm{NaOH}$ and $1 \mathrm{M}$ of $\mathrm{HCl}$ in order to remove possible organic impurities, washed with distilled water to remove all excess and basic. Finally, they were dried at $80^{\circ} \mathrm{C}$ for $3 \mathrm{~h}$. The properties of the adsorbents were measured as shown in Table S1.

Properties belonging to Iraqi soil were used as a virtual porous medium (aquifer) in the theoretical model conducted in the present study. This soil had bulk density $=1.563 \mathrm{~g} / \mathrm{cm}^{3}$, porosity $=0.42$, and particle size distribution ranged from $63 \mu \mathrm{m}$ to $0.71 \mathrm{~mm}$ with effective grain size, $d_{10}$, of $110 \mu \mathrm{m}$, a median grain size, $d_{50}$, of $180 \mu \mathrm{m}$ and a uniformity coefficient, $\mathrm{C}_{\mathrm{u}}=\mathrm{d}_{60} / \mathrm{d}_{10}$, of 1.73 .

The lead was selected as a representative of heavy metal contaminants. To simulate the water's lead contamination, a solution of $\mathrm{Pb}\left(\mathrm{NO}_{3}\right)_{2}$ (manufactured by $\mathrm{BDH}$, England) was prepared and added to the specimen to obtain representative concentration. The $\mathrm{pH}$ of this solution was adjusted by adding $0.1 \mathrm{M} \mathrm{HNO}_{3}$ or $0.1 \mathrm{M} \mathrm{NaOH}$ as required.

\subsection{Batch Experiments}

Batch experiments were conducted in order to determine the equilibrium data and to specify the preferred status for the remediation process. These statuses included the contact time, initial $\mathrm{pH}$, sorbents dosage, agitation speed, and initial concentration of $\mathrm{Pb}^{+2}$. A series of $250 \mathrm{~mL}$ of flasks were used and each flask was filled with $100 \mathrm{~mL}$ of $\mathrm{Pb}^{+2}$ solutions, which have an initial concentration of $50 \mathrm{mg} / \mathrm{L}$. $0.1 \mathrm{~g}$ of $\mathrm{ADP}, 0.2 \mathrm{~g}$ of CAC, and $0.5 \mathrm{~g}$ of $\mathrm{ZP}$ were added separately to the solutions in the flasks. The aqueous solution in every flask was stayed stirred on an orbital shaker at $200 \mathrm{rpm}$ for $150 \mathrm{~min}$. A constant magnitude $(20 \mathrm{~mL}$ ) of the aqueous solution was drawn from every flask and then passes through a filter paper kind of (Wattman No. 1) to remove the sorbents. A constant volume $10 \mathrm{~mL}$ of the filtered solution was withdrawn out for analysis to measure the concentration of the residual contaminant; these analyses were carried out by using Atomic Absorption Spectrophotometer. So, the sorbed amount of contaminant on the sorbent was determined by means of using mass balance. Kinetic studies were carried out with various $\mathrm{pH}$ values, various amounts of sorbents dosage, different values of the initial concentration of $\mathrm{Pb}^{+2}$, and finally different values of shaking speed. From the perfect experimental data, the quantity of $\mathrm{Pb}^{+2}$ kept on the solid phase (adsorbents), $q_{e}$, was determined from the following equation [20]:

$$
q_{e}=\left(C_{o}-C_{e}\right) \frac{V}{m}
$$

where $C_{e}$ and $C_{o}$ are the equilibrium and initial concentrations of $\mathrm{Pb}^{+2}$ in the aqueous phase $(\mathrm{mg} / \mathrm{L}), m$ is the mass of the adsorbents in the flask (g), and $V$ is the volume of $\mathrm{Pb}^{+2}$ in the flask (L).

\section{Description of Sorption Data}

Two isotherm models were used for the characterization of sorption data [21]: 
- Langmuir model assumes symmetric energies of sorption onto the surface and no migration of sorbate in a plane of the surface. The equation is written as follows:

$$
q_{e}=\frac{q_{m} b C_{e}}{1+b C_{e}}
$$

Where $\mathrm{q}_{\mathrm{m}}$ is the maximum sorption capacity (mg/g) and $\mathrm{b}$ is the constant depended on the free energy of sorption $(\mathrm{L} / \mathrm{mg})$.

- Freundlich model: is quantified by:

$$
q_{e}=K_{F} C_{e}^{1 / n}
$$

Where $K_{F}$ the Freundlich sorption coefficient and $n$ is is an empirical coefficient mention the intensity of the sorption.

\section{Two-dimensional Model Setup}

The mathematical modeling is a major parameter used to predict the barrier efficiency in various working conditions. The numerical modeling of simulated lead transport in groundwater was performed in a sandy unconfined aquifer model. 2D groundwater model of this aquifer demonstrates that the COMSOL Multiphysics applied to unidirectional fluid flow and $2 \mathrm{D}$ transient solute transport through an unconfined aquifer. Although the velocity of flow has a component in the transverse direction $(\mathrm{Y})$, the unidirectional fluid flow in the $\mathrm{X}$ direction was assumed in the present simulation which is fair for such situation as described by "Khebchareon" [22]. The width and length of the model were set to be $70 \mathrm{~m}$, Fig. 1. The simulation process of the PRB was limited to the two-dimensional theoretical model without a practical part. There are three kinds of PRBs in this study, namely, continuous ADP-PRB, CAC-PRB, and ZP-PRB. The continuous PRB model aquifer contained three parts, the first one performed by $40 \mathrm{~m}$ long of sandy soil shown at the left side of the aquifer, the second part was PRB ( $3 \mathrm{~m}$ thickness) located at aside soil, and the third part represented by $27 \mathrm{~m}$ long of the sandy soil which located at the right side of the PRB. The $\mathrm{Pb}^{+2}$ solution at an initial concentration equal to $0.05 \mathrm{~kg} / \mathrm{m}^{3}$ and

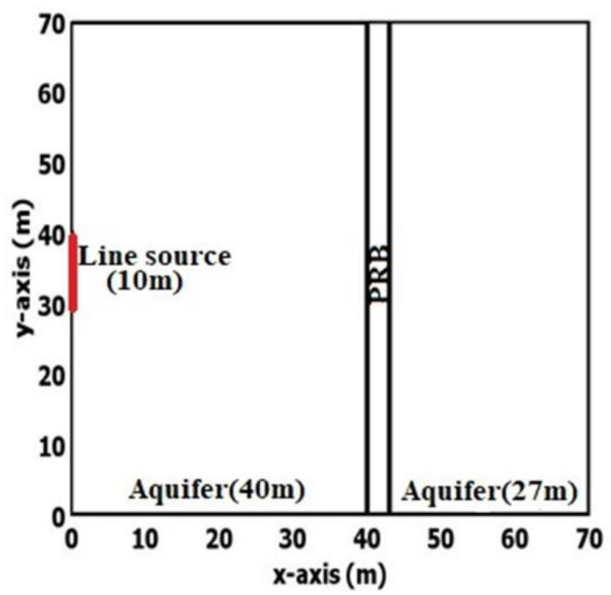

Fig. 1. The geometry of the model aquifer as plotted by COMSOL Multiphysics 3.5a. velocity $\left(V_{x}\right)=0.00008 \mathrm{~m} / \mathrm{s}$ was inserted through the model aquifer from a line source (10 $\mathrm{m}$ long) which was existing on the left side of the aquifer. The value of the inserted solution velocity was chosen to satisfy the laminar flow, i.e. Reynolds number Re $<1-10$ [23]. The line source was simulated a continuous release of contamination. It is clear here that the value of the initial lead concentration (0.05 $\mathrm{kg} / \mathrm{m}^{3}$ ) that used in this study was high in comparison to the concentration of lead in the contaminated groundwater in order to deal with case of critical pollution and demonstrate the ability of carbon produced from Iraqi date pits to remove the high level of uncontrolled lead- pollution, which often occurs near battery factories.

\section{Hydrodynamic Dispersion Coefficient $(D)$}

The effect of hydrodynamic dispersion is to cause a plume of contamination to elongate in the direction of advection as well as to develop a gradient of decreasing concentration from the center to the margins of the plume. Due to this study deal with the two-dimensional flow, Therefore, this coefficient has two values called longitudinal $\left(D_{L}\right)$ and transverse $\left(D_{T}\right)$ hydrodynamic dispersion coefficient as the following equations:

$$
\begin{aligned}
& D_{L}=\alpha_{L} V_{L}+\tau D_{d} \\
& D_{T}=\alpha_{T} V_{T}+\tau D_{d}
\end{aligned}
$$

Where $\left(\alpha_{L}, \alpha_{T}\right)$ are longitudinal and transverse dispersivity parameter $(\mathrm{m}),\left(V_{L}, B_{T}\right)$ are longitudinal and transverse velocity $(\mathrm{m} / \mathrm{s}) . \tau$ is a tortuosity factor, $D_{d}$ is diffusion coefficient $\left(\mathrm{m}^{2} / \mathrm{s}\right)$. However, the values of longitudinal dispersivity $\left(\alpha_{L}\right)$ used in the present study for PRBs and aquifers were estimated using the following equation [24]:

$$
\alpha_{L}=0.83(\log L)^{2.414}
$$

where $\mathrm{L}$ is the length of the flow path (m).

Tortuosity is a measure of the effect of the shape of the flow path followed by water molecules in a porous medium. It is calculated depending on the porosity of the medium (n) as follows [25]:

$$
\tau=n^{m-1}
$$

Archie (1942) reports values form of 1.8-2 for consolidated sandstones, 1.3 for unconsolidated sand in a laboratory experiment, and 1.3-2 for partly consolidated sand. For theoretical or conceptual work the value $\mathrm{m}=2$ is considered, which may be justified if there is no further information as cited by Holzbecher (2007) [25]. According to Fetter (1999) [24], the transverse dispersion coefficient $\left(D_{T}\right)$ adopted in the present study was equal to $10 \%$ of the longitudinal dispersion coefficient $(D L)$.

\section{Results and Discussion}

\subsection{Influence of Batch Operating Parameters}

\subsubsection{Equilibrium time and initial $\mathrm{pH}$ of the solution}

The equilibrium time should be determined to ensure achieving equilibrium concentrations. Fig. 2 shows the effect of contact time 
on $\mathrm{Pb}^{+2}$ removal using $0.1 \mathrm{~g}, 0.2 \mathrm{~g}, 0.5 \mathrm{~g}$ of $\mathrm{ADP}, \mathrm{CAC}, \mathrm{ZP}$, respectively, which are added to $100 \mathrm{~mL}$ of contaminated solution for batch tests at room temperature. It seems that the sorption was rapid at the initial stage and it was increased as a function of contact time until achieved the equilibrium state. This can be explained on the basis of presenting a large number of sites for the sorption of contaminant. However, the removal rate was gradually decreased
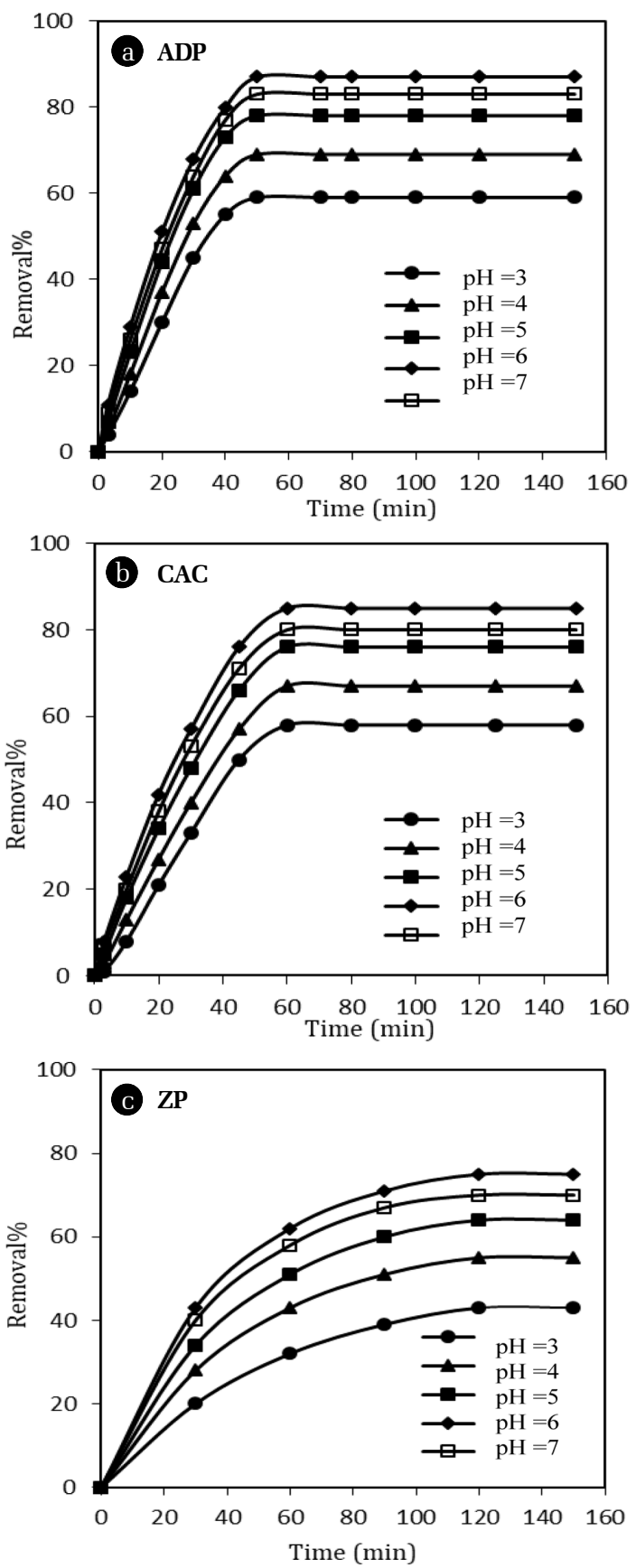

Fig. 2. Removal percent of $\mathrm{Pb}^{+2}$ onto (a) $0.1 \mathrm{~g} \mathrm{ADP} / 100 \mathrm{~mL}$, (b) $0.2 \mathrm{~g}$ $\mathrm{CAC} / 100 \mathrm{~mL}$, (c) $0.5 \mathrm{~g} \mathrm{ZP/100} \mathrm{mL}$ at different values of $\mathrm{pH}$. $(\mathrm{Co}=50 \mathrm{mg} / \mathrm{L}$, and agitation speed $=200 \mathrm{rpm})$ due to the decrease the vacant sites on the surface of the sorbent and the formation of repulsive forces [26]. The kinetic data show that the maximum removal percent mainly at 50, 60, and $120 \mathrm{~min}$ using $\mathrm{ADP}$, $\mathrm{CAC}, \mathrm{ZP}$, respectively, there was no significant change in residual concentrations after these equilibrium times. The $\mathrm{pH}$ of the aqueous solution is one of the parameters that influences and controls the sorption rate of the reactive materials for $\mathrm{Pb}^{+2}$ ions from contaminant solution because of its effect on the surface characteristics of the reactive material and the ionic shape of the contaminant in the aqueous solutions [27]. Also, Fig. 2 illustrates the effect of initial $\mathrm{pH}$ of the solution on the sorption of $\mathrm{Pb}^{+2}$ onto $\mathrm{ADP}, \mathrm{CAC}$, and $\mathrm{ZP}$. Removal of $\mathrm{Pb}^{+2}$ ions was very low at an acidic solution $(\mathrm{pH}=3)$ and this is because the presence of hydrogen ions in a large amount, and these ions will be contested with the $\mathrm{Pb}^{+2}$ for sites that existed on the sorbents. The optimum $\mathrm{pH}$ was found to be $\mathrm{pH}$ of 6 for whole studied sorbents. The maximum removal of $\mathrm{Pb}^{+2}$ efficiency was $(87 \%$, $85 \%$, and $75 \%$ ) for $\mathrm{ADP}, \mathrm{CAC}$, and $\mathrm{ZP}$, respectively. This can be explained due to reducing in a contest among metal and hydrogen types for the binding sites [28]. So, the decrease in the efficiency of removal to less this value when increasing in $\mathrm{pH}$ is as a result of forming soluble hydroxyl compounds, so the precipitation will accrue which can complicate the process of sorption and do not join to the sites that available on the sorbents surface [29].

\subsubsection{Sorbents dosage}

One of the important parameters that strongly affect the sorption capacity is the sorbent dosage. The impact of sorbent dosage on the removal of lead ions was presented in Fig. 3. The results show an increase in the lead removal efficiency as sorbent dosage increasing up to a certain limit and then it remains unchanged. An increase in the sorption with increasing dose of the sorbent is a reasonable action due to that the additional sorbent dosage leads to existing very high amounts of sorption sites, and then greater removal efficiency [30]. The relative increase in the percentage removal of lead ions is found to be insignificant after certain dosages 0.2 , $0.4,1 \mathrm{~g} / 100 \mathrm{~mL}$ of $\mathrm{ADP}, \mathrm{CAC}$, and $\mathrm{ZP}$, respectively, which is fixed as the best dosage. The data clearly show that the ADP is more effective than CAC and ZP, with removal efficiency reached $98 \%$, $97 \%$, and $85 \%$ for $\mathrm{ADP}, \mathrm{CAC}$, and $\mathrm{ZP}$, respectively.

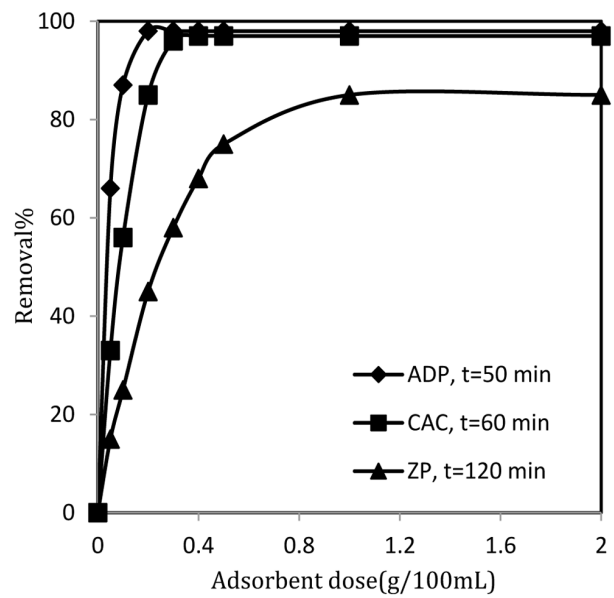

Fig. 3. Effect of $A D P, C A C, Z P$ dosages on removal percent of $\mathrm{Pb}^{+2}$ $(\mathrm{Co}=50 \mathrm{mg} / \mathrm{L}$, agitation speed $=200 \mathrm{rpm}, \mathrm{pH}=6)$. 


\subsubsection{Agitation speed}

The effect of agitation speed on the removal efficiency of $\mathrm{Pb}^{+2}$ was studied by varying the speed of agitation from 0 to $300 \mathrm{rpm}$ and keeping other parameters equal to the best ones obtained in the previous steps. Fig. 4 illustrates that about (13\%, 9\%, and $8 \%$ ) of the $\mathrm{Pb}^{+2}$ were removed before shaking (agitation speed $=0$ ) by using ADP, CAC, and ZP, respectively. There was an increase in contaminant uptake when agitation speed was increased from 0 to $200 \mathrm{rpm}$ at which about $\left(98,97 \%\right.$ ) of $\mathrm{Pb}^{+2}$ have been removed using $\mathrm{ADP}$, and CAC, respectively, and about $89 \%$ of $\mathrm{ZP}$ was removed when the agitation speed increased from 0 to $250 \mathrm{rpm}$. The high agitation speeds increase the diffusion of contaminants across the reactive medium and enhance an appropriate contact between these contaminants and the binding sites [31].

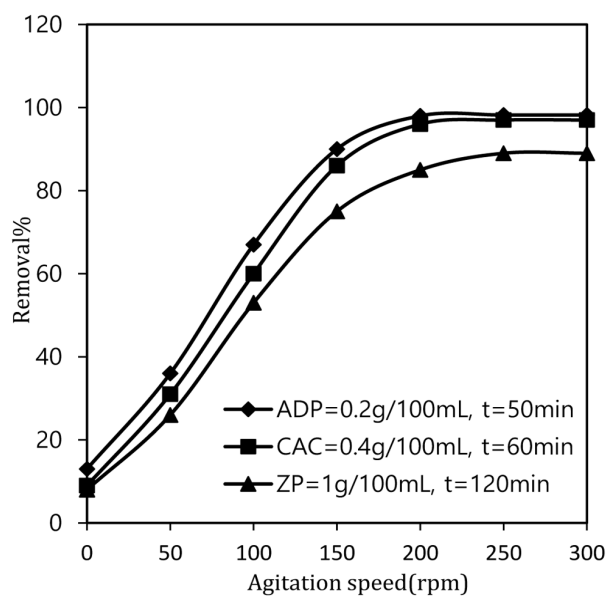

Fig. 4. Effect of agitation speed on removal percent of $\mathrm{Pb}^{+2}(\mathrm{Co}=$ $50 \mathrm{mg} / \mathrm{L}, \mathrm{pH}=6$ )

\subsubsection{Initial concentration of lead}

The effect of initial $\mathrm{Pb}^{+2}$ concentration on the sorption of $\mathrm{Pb}^{+2}$ onto $\mathrm{ADP}, \mathrm{CAC}$, and $\mathrm{ZP}$ is shown in Fig. 5. It could be seen that the percent lead removal decreased from $98 \%, 97 \%$, and $89 \%$ to $62 \%, 60 \%$, and $56 \%$ for $\mathrm{ADP}, \mathrm{CAC}$, and $\mathrm{ZP}$, respectively, with

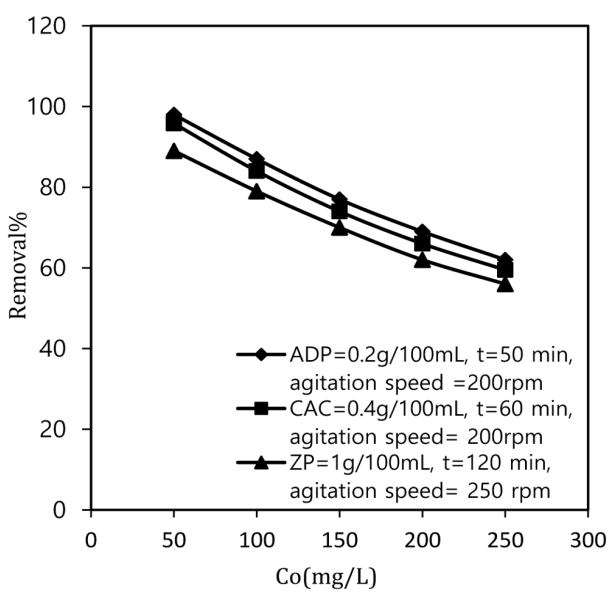

Fig. 5. Effect of initial concentration on removal percent of $\mathrm{Pb}^{+2}$ at $\mathrm{pH}=6$. the increase in initial concentration. This explains that the unit of contaminant sorbed per amount of sorbent mass decreased when the initial concentration increased. This plateau clarifies that the active sites exist on the sorbents surface is saturated with the contaminant, which indicates that unsuitable binding sites became contributory in the operation as the concentration increased [32].

\subsection{Sorption Isotherms}

The sorption data of lead have been fitted with a linearized form of two isotherm models namely Langmuir, and Freundlich as previously mentioned. The parameters for each model were obtained by fitting the models to the experimental data. The sorption isotherms of $\mathrm{Pb}^{+2}$ ions on $\mathrm{ADP}, \mathrm{CAC}$, and $\mathrm{ZP}$ are shown in Fig. S1. Table S2 represent all parameters with the coefficient of determination $\left(\mathrm{R}^{2}\right)$ were determined from the slope and intercept of the linear plot. It is clear that the Freundlich isotherm model provided relatively the best $\mathrm{R}^{2}$ in comparison with the Langmuir isotherm model for $\mathrm{Pb}^{+2}$ sorption on the ADP, CAC, and ZP. Accordingly, Freundlich isotherm model will be used to describe the sorption of $\mathrm{Pb}^{+2}$ in the partial differential equation governing the transport of $\mathrm{Pb}^{+2}$ undergoing equilibrium sorption through ADP, CAC, and $\mathrm{ZP}$ as PRBs in the theoretical continuous model. Fig. S2 presents a comparison between experimental results of the sorbed amount of $\mathrm{Pb}^{+2}$ onto sorbents with theoretical values calculated by the Freundlich model. However, the fitness between the experimental and theoretical values was generally good with root mean squared error (RMSE) not exceeded the 0.029 [33]. Also, it is clear that the lead has a stronger sorptive property to ADP in comparison with CAC and ZP as its isotherm is located in an upper position in this plot.

\subsection{Fourier Transform Infrared Analysis (FTIR)}

FTIR is considered as a kind of direct means for investigating the sorption mechanisms by identifying the functional groups responsible for lead binding. Infrared spectra of ADP, CAC, and ZP samples before and after biosorption of lead were examined using a Shimadzu FTIR, 8000 series spectrophotometer within range of $400-4,000 \mathrm{~cm}^{-1}$ shown in Fig. S3. The shifts in the infrared frequencies support that Alkyl halides, Alcohols, and Carboxylic acid are the functional groups responsible for the sorption of lead onto ADP and CAC. While $\mathrm{SiO}_{4}, \mathrm{AlO}_{4}$, and Hydroxyl group are responsible for the sorption of lead onto ZP [34]. The contributions of functional groups in the sorption operation are shown in Table S3.

\subsection{Two-dimensional Model Setup}

The two-dimensional advection-dispersion equation is an effective and efficient tool for quantifying the contaminant distribution in the aquifer and PRB systems. This equation, resolved by COMSOL Multiphysics 3.5a software, is considered accurate for such system adopted here where the contaminated water has a unidirectional velocity in the longitudinal direction of the flow and the hydrodynamic dispersion coefficient in $\mathrm{X}$ and $\mathrm{Y}$ directions. The dissolved lead mass balance equation can be written as follows [35]:

$$
D_{x} \frac{\partial^{2} C}{\partial x^{2}}+D_{y} \frac{\partial^{2} C}{\partial y^{2}}-v_{x} \frac{\partial C}{\partial x}=\frac{\partial C}{\partial t}+\frac{\rho b}{n} \frac{\partial q}{\partial t}
$$


Where $\mathrm{C}$ is the $\mathrm{Pb}^{+2}$ concentrations in water, $\mathrm{q}$ is the $\mathrm{Pb}^{+2}$ concentrations on solid, $\mathrm{n}$ is the porosity of the media, and $\rho_{\mathrm{b}}$ is the dry sorbing material bulk density. Under the isotherm conditions, the second term (q) on the right-hand side of this equation can be replaced with Freundlich model Eq. (3). Table S4 summarizes the model geometry and boundary value problem for the simulated two-dimensional model adopted in the present study.

\subsubsection{Transport of $\mathrm{Pb}^{+2}$ through aquifer model}

Fig. 6 shows the predicted contour plot of transport modeling results of lead-contaminated groundwater with $\mathrm{C}_{0}=0.05 \mathrm{~kg} / \mathrm{m}^{3}$ and velocity
$\left(V_{x}\right)=0.00008 \mathrm{~m} / \mathrm{s}$ across the aquifer model in four different cases (without PRB, ADP-PRB, CAC-PRB, and ZP-PRB) after 1 and 50 d. It is clear that the direction of the transport process of lead due to advection and dispersion is from high concentration gradient on the left-hand side to the lower one on the right side, and the contaminant plume is hindered by the PRB which led to the fact that the concentrations reaching the outlet of the aquifer model region with presence of $\mathrm{PRB}$ were lower than that of the first case (without PRB). Also, the ADP-PRB impairs the progress of the pollutant more than in the case of CAC-PRB and ZP-PRB in the barrier

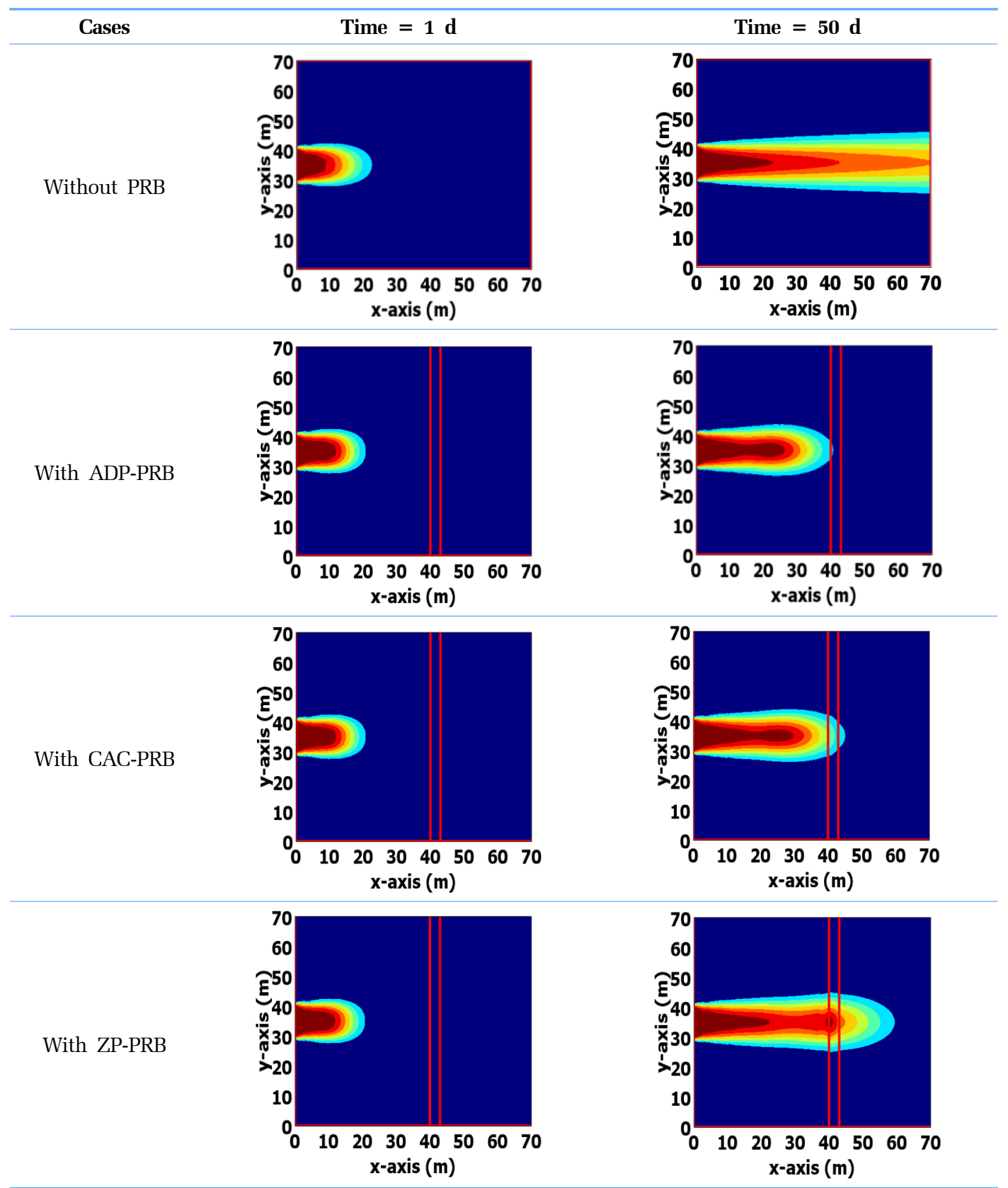

Fig. 6. Contour plot of lead concentration across the aquifer model after 1 and $50 \mathrm{~d}$. 
region for same velocity and travel time. This can be attributed to the difference in affinity of lead for binding sites of ADP, CAC, and $\mathrm{ZP}$, which is higher for $\mathrm{ADP}$ in comparison with $\mathrm{CAC}$ and $\mathrm{ZP}$.

\subsubsection{Performance of PRBs}

After reaching the $\mathrm{PRB}$, the lead-contaminated groundwater with $\mathrm{C}_{\mathrm{o}}=0.05 \mathrm{~kg} / \mathrm{m}^{3}$ and velocity $=0.00008 \mathrm{~m} / \mathrm{s}$ is treated and its concentration is reduced by the sorption process. Relationships between time and concentration of lead-contaminated groundwater leaving (outflow) the PRB at the point $(43,35)$ are presented in Fig. 7. The main results that can be obtained from this figure that the three types of PRBs can be used successfully to treat lead-contaminated groundwater and the PRBs begin to saturate when the travel time increasing. The performance of the PRBs is the time required to preserve the contaminant concentration downgradient less than the maximum contaminant level (MCL) that could be present in drinking water (MCL for lead $=1 \times 10^{-5} \mathrm{~kg} / \mathrm{m}^{3}$ ) [36]. The ADP-PRB have a higher operation time in comparison with the CAC-PRB, and ZP-PRB since the outflow lead concentration of CAC-PRB and ZP-PRB reached the MCL faster than ADP-PRB as illustrated in Fig. 7. According to the above results, the operation time is equal to 50, 34, and $20 \mathrm{~d}$ for ADP, CAC, ZP barriers, respectively. So that the arrangements of PRBs depending on operation time are as the following:

\section{ADP-PRB > CAC-PRB > ZP-PRB}

These results are reasonable and compatible with results of batch processes which proved that the ADP has a higher lead sorption capacity in comparison with CAC and ZP.

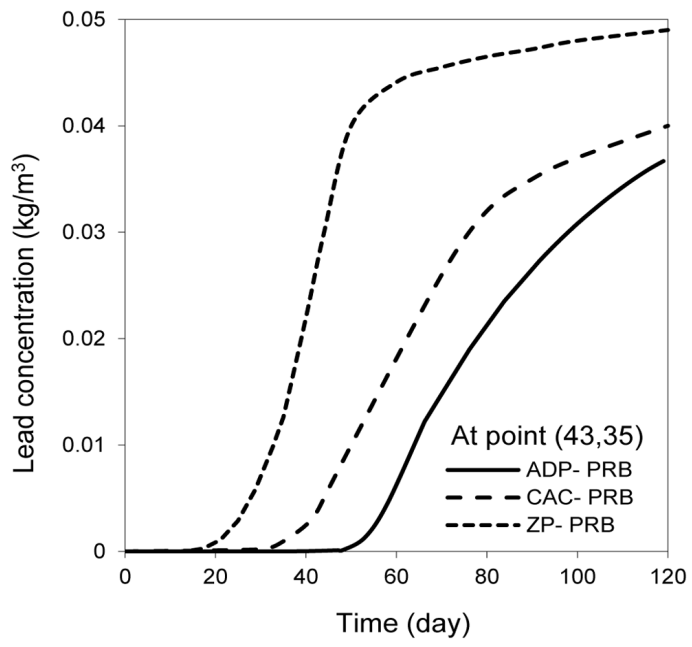

Fig. 7. Lead concentration and time relationship.

\subsubsection{Lead removal within PRBs}

Lead concentration and time relationship at points within the thickness of PRBs (3m) are shown in Fig. 8. It is obviously seen that the lead concentration at P1 $(41,35)$ increases more rapidly than the P2 $(42,35)$ or P3 $(43,35)$. The increment in lead concentration at this point indicates that the reactive materials have been lost its sorption ability for lead at the front part of the barrier rather
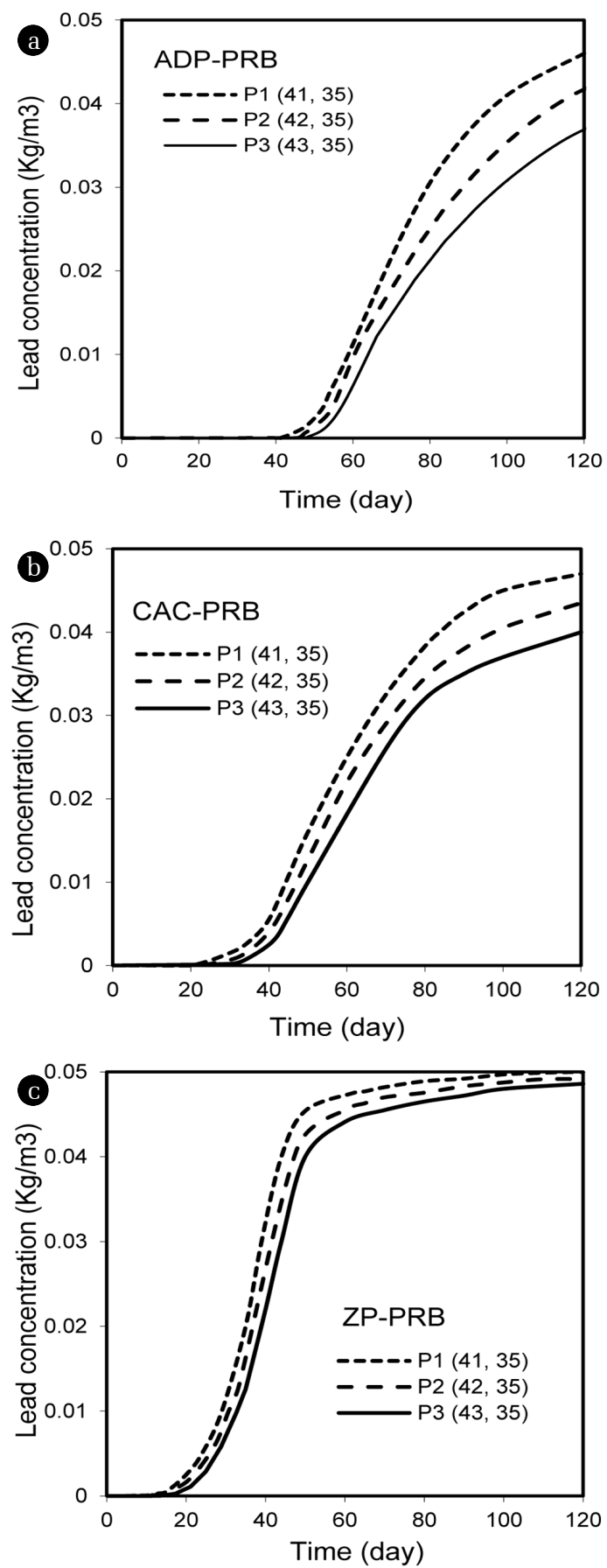

Fig. 8. Lead concentration and time relationship at different points within the thickness of barriers.

than the inner or end parts, at the front part; it would be in contact with high concentration of oncoming contaminated groundwater, therefore, the reactive materials would have reached its maximum sorption ability early, and the lead concentrations start to increase as shown in Fig. 8. On the other hand, the reactive materials at the end of barrier thickness (P3 $(43,35)$ ) would have reached its maximum sorption ability in a longer time than the front one since 
it would be in contact with lower concentrations of oncoming contaminated groundwater in most of the times of simulation.

\section{Conclusions}

1) Contact time, initial $\mathrm{pH}$ of the solution, sorbent dosage, agitation speed, and initial concentration of the contaminant were most of the parameters affected by the sorption process between $\mathrm{Pb}^{+2}$ ions and sorbents. The best values of these parameters that will achieve the maximum removal efficiency of $\mathrm{Pb}^{+2}$ were (50 min, 6, $0.2 \mathrm{~g} \mathrm{ADP} / 100 \mathrm{~mL}, 200 \mathrm{rpm}, 50 \mathrm{mg} / \mathrm{L}$ ), (60 min, 6, 0.4 g CAC/100 mL, $200 \mathrm{rpm}, 50 \mathrm{mg} / \mathrm{L}$ ), and (120 min, 6, $1 \mathrm{~g} \mathrm{ZP/100}$ $\mathrm{mL}, 250 \mathrm{rpm}, 50 \mathrm{mg} / \mathrm{L}$ ) for ADP, CAC, and $\mathrm{ZP}$, respectively.

2) Sorption data of lead on the sorbents were well correlated by Freundlich sorption model with $\mathrm{R}^{2}$ not less than 0.99 . It was found that ADP is more effective for removal of $\mathrm{Pb}^{+2}$ than CAC and ZP. The maximum sorption capacities for ADP, CAC, and $\mathrm{ZP}$ were $24.5,12.125$, and $4.45 \mathrm{mg} / \mathrm{g}$, respectively.

3) FTIR analysis proved that the sorption of lead onto ADP and CAC was achieved depended on Alkyl halides, Alcohols, and Carboxylic acid functional groups. While the groups that responsible for the sorption process onto $\mathrm{ZP}$ are $\mathrm{SiO}_{4}, \mathrm{AlO}_{4}$, and Hydroxyl,

4) The $2 \mathrm{D}$ numerical solution shows that the contaminant plume is hindered by PRB and the concentrations reaching the outlet of the model region with the presence of PRB were lower than that of without PRB (soil only).

5) The propagation of contaminated plume is restricted by the ADP in the barrier region. The same behavior can be recognized for CAC and ZP but the contaminant front will be faster than that of $\mathrm{ADP}$ for same velocity and travel time.

6) The ADP-PRB have higher operation time in comparison with the CAC - PRB, and ZP-PRB since the outflow lead concentration of CAC-PRB and ZP-PRB reached the MCL faster than ADP-PRB. The operation time is equal to 50, 34, and $20 \mathrm{~d}$ for $\mathrm{ADP}, \mathrm{CAC}$, ZP barriers, respectively.

\section{References}

1. Natale F, Natale MD, Greco R, Lancia A, Laudante C, Musmarra D. Groundwater protection from cadmium contamination by permeable reactive barriers. J. Hazard. Mater. 2008;160:428-434.

2. Reddy DHK, Harinath Y, Seshaiah K, Reddy AVR. Biosorption of $\mathrm{Pb}$ (II) from aqueous solutions using chemically modified moringa oleifera tree leaves. Chem. Eng. J. 2010;162: 626-634.

3. Liu Y, Liu Z, Gao J, Dai J, Han J. Selective adsorption behavior of $\mathrm{Pb}(\mathrm{II})$ by mesoporous silica SBA-15-supported $\mathrm{Pb}$ (II)-imprinted polymer based on surface molecularly imprinting technique. J. Hazard. Mater. 2011;186:197-205.

4. Mieles J, Zhan H. Analytical solutions of one-dimensional multispecies reactive transport in a permeable reactive barrier-aquifer system. J. Contam. Hydrol. 2012;135:54-68.

5. Hashim MA, Soumyadeep M, Jaya NS, Bhaskar S. Remediation technologies for heavy metal contaminated groundwater. J. Environ. Manage. 2011;92:2355-2388

6. National Research Council. Alternatives for groundwater clean- up, National Academy Press, Washington D.C. 1994; 315

7. Lihui H, Gaofeng L, Guihua D, Xueyuan W, Chuang W, Yangyang L. Reaction mechanism of zero-valent iron coupling with microbe to degrade tetracycline in permeable reactive barrier (PRB). Chem. Eng. J. 2017;316:525-533.

8. Faisal AH, Abd Ali ZT. Remediation of groundwater contaminated with the lead-phenol binary system by granular dead anaerobic sludge-permeable reactive barrier. Environ. Technol. 2017;38:2534-2542.

9. Junchao M, Geoffrey WS, Kathryn MA. The effect of temperature on hydrocarbon adsorption by diphenyldichlorosilane coated zeolite and its application in permeable reactive barriers in cold regions. Cold Reg. Sci. Technol. 2018;145:169-176.

10. Ziad T, Abd Ali, Hussain MF, Mohammed AI. Numerical modeling of performance of olive seeds as permeable reactive barrier for containment of copper from contaminated groundwater. Desalin. Water Treat. 2019;139:268-276.

11. Chandra PD, Sahu JN, Mohanty C, Rajphan B, Bhim Charan M. Column performance of granular activated carbon packed bed for Pb(II) removal. J. Hazard. Mater. 2008;156:596-603.

12. Martinez M, Torres M, Guzman C, Maestri D. Preparation and characteristics of activated carbon from olive stones and walnuts shells. Ind. Crop. Prod. 2006;23:23-28.

13. Ayad AHF, Ziad TAA. Using granular dead anaerobic sludge as permeable reactive barrier for remediation of groundwater contaminated with phenol. J. Environ. Eng. 2014;141.

14. Zhao P, Yu F, Wang R, Ma Y, Wu Y. Sodium alginate/graphene oxide hydrogel beads as permeable reactive barrier material for the remediation of ciprofloxacin-contaminated groundwater. Chemosphere 2018;200:612-620.

15. Dawit NB, Jianhua D, Leandro GF, Megharaj M, Sreenivasulu C, Ravi N. Actively facilitated permeable reactive barrier for remediation of TCE from a low permeability aquifer: Field application. J. Hydrol. 2019;572:592-602.

16. Oriol G, Antoine A, Hayley D, Trevor E, Robert M. Performance of a field-scale biological permeable reactive barrier for in-situ remediation of nitrate-contaminated groundwater. Sci. Total Environ. 2019;659:211-220.

17. COMSOL. Multiphysics User's Manual, 2008 [Internet]. COMSOL Inc; c2008 [cited September 2008]. Available from: www.comsol.com/support/forums.

18. Mohamed OS, Jamal A, Khaled A. Adsorption of $\mathrm{CO}_{2}$ by activated carbon from date stones filled into a local design of automobile exhaust. Int. J. Eng. Technol. 2013;2:1:113.

19. Alexander P, Zayas I. Particle size and shape effects on adsorption rate parameters. Environ. Eng. 1989;115:41-55.

20. Wang J, Chen C. Bio-sorbents for heavy metals removal and their future. Biotechnol. Adv. 2009;27:195-226.

21. Hamdaoui O, Naffrechoux E. Modeling of adsorption isotherms of phenol and chlorophenols onto granular activated carbon. J. Hazard. Mater. 2007;147:381-394.

22. Khebchareon M. Crank-Nicolson finite element for 2-D groundwater flow, advection-dispersion, and interphase mass transfer. I: Model development. Int. J. Numer. Anal. Mod. Series B. Comput. Inform. 2012;3:109-125.

23. Delleur J. The handbook of groundwater engineering. Boca Raton: Springer-Verlag; 1998. 
24. Fetter CW. 1999. Contaminant hydrogeology. 2nd ed. New Jersey: Prentice-Hall; 1999.

25. Holzbecher E. 2007. Environmental modeling using MATLAB. Berlin Heidelberg: Springer; 2007.

26. Gamal ES, Dessouki HA, Ibrahim SS. Biosorption of Ni(II) and Cd(II) ions from aqueous solutions onto rice straw. Chem. Sci. J. 2010;9:1-11.

27. Garg UK, Kaur M, Garg VK, Sud D. Removal of hexavalent chromium from aqueous solution by agricultural waste biomass. J. Hazard. Mater. 2007;140:60-68.

28. Raji C, Manju G, Anirudhan TS. Removal of heavy metal ions from water using sawdust-based activated carbon. Indian J. Eng. Mater. 1997;4:254-260.

29. Alkan M, Kalay B, Dog־an M, Demirbas O. Removal of copper ions from aqueous solutions by kaolinite and batch design. J. Hazard. Mater. 2008;153:867-876.

30. Amarasinghe B, Williams RA. Tea waste as a low-cost adsorbent for the removal of $\mathrm{Cu}$ and $\mathrm{Pb}$ from wastewater. Chem. Eng. J. 2007;132:299-309.

31. Anwar J, Zaman W, Shafique U, Salman M, Dar A, Anwar S. Removal of $\mathrm{Pb}(\mathrm{II})$ and $\mathrm{Cd}(\mathrm{II})$ from water by adsorption on peels of banana. Bioresour. Technol. 2010;101:1752-1755.

32. Riaz Q, Rehan A. A study of the adsorption of phenol by activated carbon from aqueous solutions. Turk. J. Chem. 2002;26:357-361.

33. P Andrson M, Woessner W. Applied groundwater modeling: simulation of flow and advective transport. 2nd ed. San Diego: Academic Press; 1992.

34. Włodzimierz M, Magdalena K, Katarzyna B. FT-IR studies of zeolites from different structural groups. Chemik 2011;65:667-674.

35. Reddi LN, Inyang H. Geoenvironmental engineering principles and applications. New York: Marcel Dekker; 2000.

36. World Health Organization. Guidelines for drinking water quality. Health criteria and other supporting information. 2nd ed. Geneva: World Health Organization; 1996. 